\title{
LA DOBLE INCRIMINACIÓN EN EL SISTEMA DE LA EUROORDEN O DE LA NECESIDAD DE UNA EXÉGESIS REALISTA DEL PRINCIPIO DE RECONOCIMIENTO MUTUO. APUNTES EN RELACIÓN CON EL ASUNTO PUIGDEMONT
}

\author{
FLORENTINO-GREGORIO RUIZ YAMUZA ${ }^{1}$ \\ Audiencia Provincial de Huelva \\ fg.ruiz@poderjudicial.es
}

Cómo citar/Citation

Ruiz Yamuza, F. G. (2018).

La doble incriminación en el sistema de la Euroorden o de la necesidad de una exégesis realista del principio de reconocimiento mutuo. Apuntes en relación con el asunto Puigdemont. Revista de Derecho Comunitario Europeo, 61, 1059-1090. doi: https://doi.org/10.18042/cepc/rdce.61.07

\section{Resumen}

Conocer el funcionamiento de la orden europea de detención y entrega (OEDE), basada en el principio de reconocimiento mutuo, requiere una comprensión profunda del mismo y un análisis realista libre de expectativas apartadas de su real operatividad.

El requisito de la doble incriminación, con características singulares en la OEDE, sigue modelos de transposición de los Estados miembros que en ocasiones elevan la falta correspondencia típica de la categoría de motivo facultativo de denegación a la de motivo obligatorio, con lo que, de facto, la falta de doble incriminación equivale indefectiblemente a una denegación de la entrega.

1 Magistrado Sección Tercera de la Audiencia Provincial de Huelva. Miembro de la Red Judicial Española de Cooperación Judicial Internacional (REJUE); División Penal. 
Frecuentemente la correspondencia de delitos entre Estados miembros no es total, resultando los hechos solo parcialmente coincidentes con la definición del Código Penal del Estado miembro de ejecución o constitutivos de un delito diferente de aquel por el que se reclama la entrega.

Estos factores son objeto de análisis, a la luz de la jurisprudencia del Tribunal de Justicia de la Unión Europea (TJUE), con motivo de un supuesto concreto de aplicación de los arts. 2.4 y 4.1 de la decisión marco OEDE y de la legislación alemana de transposición, IRG, que resultan representativos de la problemática existente.

\section{Palabras clave}

Cooperación judicial internacional; reconocimiento mutuo; Decisión Marco 2002/584; doble incriminación; jurisprudencia; Tribunal de Justicia de la Unión Europea.

\section{THE DOUBLE CRIMINALITY IN THE EUROPEAN ARREST WARRANT SYSTEM: THE NEED FOR A REALISTIC EXEGESIS OF THE PRINCIPLE OF MUTUAL RECOGNITION. NOTES REGARDING THE PUIGDEMONT CASE}

\section{Abstract}

Getting to know the functioning of the European Arrest Warrant (EAW), based on mutual recognition, requires a deep understanding of this principle and a realistic analysis free of expectations set aside of its real operability.

The requisite of double criminality in extradition matters, with unique characteristics in the EAW, follows transposition patterns that have on many occasions chosen to raise the lack of correspondence from the category of optional ground for a refusal to mandatory ground, which de facto equals the lack of double criminality to a refusal of surrender.

Frequently the correspondence of crimes between Member States is not exact, the facts are partially coincident with the definition of the Criminal Code of the Member State of execution or do constitute a crime but different from that for which the surrender is requested.

These factors are subject to analysis, in light of the Court of Justice of the European Union (CJEU) case law, on the grounds of a specific case of application of Arts. 2.4 and 4.1 of the EAW Framework Decision (EAW FD) and the German transposition legislation, IRG, which are representative of the existing problems.

\section{Keywords}

International judicial cooperation; mutual recognition; Framework Decision 2002/584; double criminality; jurisprudence; Court of Justice of the European Union. 


\section{LA DOUBLE INCRIMINATION DANS LE MANDAT D'ARRÊT EUROPÉEN: LA NÉCESSITÉ D'UNE EXÉGÈSE RÉALISTE DU PRINCIPE DE RECONNAISSANCE MUTUELLE. NOTES CONCERNANT L'AFFAIRE PUIGDEMONT}

\section{Résumé}

Connaître le fonctionnement du Mandat d'Arrêt Européen (MAE), basé sur la reconnaissance mutuelle, nécessite une compréhension profonde de ce principe, qui nous place dans une position réaliste d'analyse libre des attentes loin de son fonctionnement réel.

L'exigence de double incrimination en matière extraditionnelle présente des caractéristiques uniques dans le MAE. Les modèles de transposition des États membres ont souvent choisi de relever le manque de correspondance typique de la catégorie des motifs optionnels de refus au motif obligatoire, avec lequel, de facto, l'absence de double incrimination est infailliblement équivalente à un refus de livraison.

Fréquemment, la correspondance subsistante des crimes entre États membres n'est pas totale, les faits ne coïncidant que partiellement avec la définition du Code Pénal de l'État membre d'exécution ou constituant un crime différent de celui pour lequel la livraison est demandée.

Ces facteurs sont analysés, à la lumière de la jurisprudence de la Cour de Justice de l'Union Européenne (CJUE), sur la base d'un cas concret d'application des arts. 2.4 et 4.1 de la Décision-cadre du MAE et la législation allemande de transposition, IRG, qui sont représentatives des problèmes existants.

\section{Mots clés}

Coopération judiciaire internationale; reconnaissance mutuelle Décision-cadre 2002/584; double incrimination; jurisprudence; Cour de Justice de l'Union Européenne. 


\section{SUMARIO}

I. INTRODUCCIÓN: 1. El modelo de cooperación judicial en materia penal basado en el reconocimiento mutuo. 2. La Orden Europea de Detención y Entrega como exponente del sistema. II. LA DOBLE INCRIMINACIÓN EN LA DECISIÓN MARCO OEDE: 1. Los artículos 2.4 y 4.1 de la Decisión Marco OEDE. Su transposición. 2. Jurisprudencia del TJUE a propósito de la interpretación del principio de doble incriminación. III. EL ASUNTO PUIGDEMONT. IV CONCLUSIONES. BIBLIOGRAFía.

«Pero si el emperador no lleva ningún traje! ¡Fijaos, fijaos, está desnudo!».

El traje nuevo del emperador. Hans Christian Andersen

\section{INTRODUCCIÓN}

La actualidad del asunto Puigdemont ha trasladado a la opinión pública el debate acerca de la eficiencia la euroorden, de la dificultad, en un caso aparentemente claro, de obtener la colaboración de otro Estado miembro de la Unión Europea. ¿Estaremos ante un instrumento que, como el traje del emperador, más allá de su deslumbrante apariencia no es más que una ilusión y cuya aplicación efectiva muestra las desnudeces del sistema?

Las premisas que alientan la polémica deben revisarse planteando dos cuestiones básicas. Primera: ¿qué debemos esperar de un sistema de cooperación judicial penal basado en el reconocimiento mutuo?; y segunda: ¿̨cuál es la dinámica de aplicación del principio en el seno de la Unión Europea y en los propios Estados miembros?

Estas dos claves nos guiarán en el estudio de la doble criminalidad en relación con los arts. 2.4 y 4.1 de la decisión marco sobre la orden europea de detención y entrega ${ }^{2}$ (DM OEDE). Y ello al hilo de la causa especial seguida

2 Decisión Marco 2002/584/JAI del Consejo, de 13 de junio de 2002 relativa a la orden de detención europea y a los procedimientos de entrega entre Estados miembros (DO L 190, de 18 de julio de 2002, p. 1). 
ante el Tribunal Supremo al núm. 20907/2017, en la que el 21 de marzo de 2018 se dictó auto de procesamiento contra trece investigados ${ }^{3}$, y se emitió OEDE relativa a Carles Puigdemont.

\section{EL MODELO DE COOPERACIÓN JUDICIAL EN MATERIA PENAL BASADO EN EL RECONOCIMIENTO MUTUO}

El art. 67 del Tratado de Funcionamiento de la Unión Europea (TFUE) señala que la Unión constituye un Espacio de Libertad, Seguridad y Justicia y diseña dos estrategias fundamentales de cooperación judicial: armonización legislativa y reconocimiento mutuo de resoluciones ${ }^{4}$.

La aproximación de legislaciones se ha desarrollado respecto de ámbitos delictivos de especial gravedad, con repercusión transfronteriza y también, como subraya Arroyo Zapatero (2013: 15), respecto de la parte general del derecho penal y determinados principios jurisdiccionales.

El Consejo de Tampere ${ }^{5}$ consagró la cooperación basada en el reconocimiento mutuo como "piedra angular» del sistema, abarcando en la actualidad casi cualquier tipo de cooperación judicial penal en la Unión Europea (De Jorge Mesas, 2016).

Tal modelo de cooperación no opera, sin embargo, de forma automática. Para comprender mejor su real virtualidad hemos de analizar la "composición química» del principio de reconocimiento mutuo, lo que podemos realizar siguiendo el debate que describe Hoyos Sancho (2005: 812-830) entre la concepción amplia (Vogel, 2004: 26) y restringida del mismo.

La primera se sustenta en los principios de equivalencia y confianza (Gómez de Liaño Fonseca-Herrero, 2006: 158). Conforme al de equivalencia, o de Estado de procedencia, se presume que las decisiones de un tribunal extranjero se equipararían a las de un tribunal nacional. El principio de confianza, no confianza ciega, como precisan Lenaerts (2015: 3 y ss.), Bang Fuglsang (2016) o Bay Larsen (2012:140), establece que el Estado del que procede la solicitud de cooperación participa de un acervo jurídico común, con reglas procesales y un marco de respeto a los derechos humanos equiparables.

3 Resolución confirmada por el Tribunal Supremo mediante Auto de 26 de junio de 2018, ES:TS:2018:6972A.

4 Sobre la evolución de los sistemas penales nacionales post-Lisboa véase Mitsilegas (2016).

5 Consejo Europeo de Tampere, 15 y 16 de octubre de 1999. Conclusiones de la presidencia, conclusión núm. 37. Disponible en: http://www.europarl.europa.eu/summits/tam_es.htm. 
La segunda concepción sostiene que la aplicación de los instrumentos de reconocimiento mutuo queda matizada en tres dimensiones: primero, por la observancia de los requisitos de lo que Vogel (2001a: 940 y ss.) denomina orden público europeo: básicamente derechos reconocidos en el CEDH y en la CDFUE; segundo, por la necesidad de compatibilizar marcos penales no suficientemente armonizados; y tercero, por los sistemas de garantías procesales de cada Estado miembro. A tales condicionantes se añade la posición reluctante de los Estados a ceder soberanía en una materia tan sensible como la extradición, actitud que Vogel (2007: 170) denomina "proteccionismo nacional» ${ }^{6}$.

De presente, el citado debate se inclina en favor de la concepción restringida, a pesar de los avances en materia de armonización legislativa, y homogeneización de derechos procesales en la Unión, conforme al art. 82.2 b) y d) del TFUE, y la hoja de ruta del Consejo ${ }^{7}$, con la promulgación de sucesivas directivas al respecto.

\section{LA ORDEN EUROPEA DE DETENCIÓN Y ENTREGA COMO EXPONENTE DEL SISTEMA ${ }^{8}$}

De importancia capital (Alonso Moreda, 2017), como pionera del sistema de reconocimiento mutuo y por su objeto; junto con la DM 2008/909 sobre traslado de personas condenadas ${ }^{9}$, la OEDE se ocupa de la extradición, capítulo en que los Estados son más celosos de su soberanía.

$\mathrm{Su}$ diseño puede corresponderse con la concepción restringida antes mencionada. Así, los motivos de rechazo de la OEDE (arts. 3 y 4 de la DM), en apariencia limitados, ofrecen amplio margen interpretativo, especialmente los facultativos, lo que sugiere a Miguel Zaragoza (2003:8) que no estamos tan lejos de un sistema extradicional clásico. Asimismo, las garantías adicionales del art. 5 nos obligan a un cuidadoso escrutinio de su originalidad y

6 Véase también Nieto Martín (2018), sobre orden público e identidad nacional en el reconocimiento mutuo.

7 Resolución del Consejo de 30 de noviembre de 2009 sobre un plan de trabajo para reforzar los derechos procesales de sospechosos o acusados en los procesos penales (DO C 295, de 4 de diciembre de 2009, p. 1).

8 Para un estudio práctico actualizado sobre la OEDE, véase Jimeno Bulnes y Ruz Gutiérrez (2015: 35-104).

9 Decisión Marco 2008/909 del Consejo, de 27 de noviembre de 2008, relativa a la aplicación del principio de reconocimiento mutuo de sentencias en materia penal por las que se imponen penas u otras medidas privativas de libertad a efectos de su ejecución en la Unión Europea (DO L 327, de 5 de diciembre de 2008, p. 27). 
avance para evitar una exégesis maximalista del instrumento. En igual sentido, la extradición de nacionales tiene su contrapunto en los arts. 4.6 y 5.3; los principios de territorialidad y jurisdicción nacional continúan vigentes; la brevedad de plazos para tramitar las solicitudes (sesenta días máximo, según el art. 17.3) se ve comprometida en ocasiones por recursos con efecto suspensivo (validados por el TJUE en el asunto $F$.) ${ }^{10}$ que dilatan procesos, como muestran los famosos casos Melloni ${ }^{11}$ y Assange ${ }^{12}$, que tardaron años en resolverse.

Por otro lado, la jurisprudencia del TJUE subraya la trascendencia del art. 1.3 de la DM OEDE, reiterando que los derechos fundamentales no pueden verse afectados por la aplicación del instrumento, como recuerdan Ruiz Yamuza (2017: 219-228), a propósito del asunto Aranyosi-Caldararu ${ }^{13}$, y con anterioridad Peers $(2011: 1)^{14}$.

Situando la primera de las dos preguntas que nos hacíamos más arriba en el contexto de la OEDE, en cuanto a qué expectativas debemos albergar de su aplicación como paradigma (Vidal Fernández y Arangüena Fanego, 2005: 52-56), en principio presenta una utilización extensiva y satisfactoria. Las evaluaciones de la Comisión ${ }^{15}$ y del Parlamento Europeo ${ }^{16}$ son positivas, aunque apuntando áreas problemáticas y margen de mejora. Pero el examen de las estadísticas refleja un importante desfase entre las órdenes emitidas y las ejecutadas (el portal de la Comisión Europea European e-Justice ofrece para 2015 la cifra de 16144 órdenes emitidas frente a 5304 ejecutadas, con datos análogos para toda la serie 2005-2015) ${ }^{17}$, lo cual muestra una eficacia lejos de los esquemas de cooperación nacional, y un impacto no tan revolucionario como auspiciara Plachta (2003: 170 y 178).

10 Sentencia de 30 de mayo de 2013, F., C-168/13, EU:C:2013:358.

11 Sentencia de 26 de febrero de 2013, Melloni, C-399/11, EU:C:2013:107.

12 Julian Assange $v$ The Swedish Prosecution [2011] EWHC, Admin. 2849.

13 Sentencia de 5 de abril de 2016, Aranyosi-Caldararu, (C-404/15 y 659/15), EU:C:2016:198.

14 Para una panorámica general de la relación derechos fundamentales y reconocimiento mutuo, véase Klip (2016).

15 Informe de la Comisión al Parlamento Europeo y al Consejo sobre la aplicación desde 2007 de la decisión marco del Consejo de 13 de junio de 2002 relativa a la orden de detención europea y a los procedimientos de entrega entre Estados miembros. Bruselas, 11.4.2011, COM (2011), 175 final, CELEX:52011DC0175.

16 Resolución del Parlamento Europeo, de 27 de febrero de 2014, con recomendaciones destinadas a la Comisión sobre la revisión de la orden de detención europea [2013/2109(INL)], CELEX: 52014IP0174.

17 European e-Justice Portal, European Arrest Warrant. Última actualización: 12.02.2018. Disponible en: https://bit.ly/2P4QyNC. 


\section{LA DOBLE INCRIMINACIÓN EN LA DECISIÓN MARCO OEDE}

Abordaremos a continuación la segunda de las cuestiones enunciadas: ¿cómo se articula la aplicación práctica del principio de reconocimiento mutuo, tanto en el plano internacional como en derecho interno, en relación con la doble incriminación de conductas?

La doble incriminación puede estudiarse in abstracto, comparando las legislaciones del Estado requirente y del requerido, para comprobar si la conducta está tipificada en ambos; o in concreto, con completa verificación de identidades objetivo-subjetivas y apreciación de las todas las circunstancias concurrentes, para concluir que el hecho sería delito en ambos Estados (Bassiouni, 1974: 332; Plachta, 1989:109). La comparación in abstracto se referiría a conductas apriorísticamente consideradas; y la comparación in concreto, a hechos realmente acontecidos.

Interesante resulta la aportación de Falkiewicz (2018: 158) subrayando el matiz diferenciador entre las vertientes substantiva y procedimental de la doble criminalidad. La primera atañe a la lex loci o comprobación en el lugar donde se cometió el hecho, Estado de emisión, de que este es constitutivo de delito; y la segunda relativa a la lex fori, o verificación de si el mismo hecho delictivo lo sería también de haberse cometido en el lugar en el que se ha de evaluar la correspondencia, Estado de ejecución.

$\mathrm{La}$ OEDE, en esta materia, supuso un singular paso adelante respecto de los modelos no tradicionales más avanzados como el Convenio relativo a la extradición entre los Estados miembros de la $\mathrm{UE}^{18}$, que en su art. 2.1 contempla la doble incriminación como requisito para la extradición. La evolución que supone el sistema de la OEDE resulta muy relevante (aun apartándose de la propuesta de la Comisión ${ }^{19}$, cuyo art. 27 preveía que cada Estado miembro publicase una lista de conductas por las que no concedería la extradición al no ser típicas en su ordenamiento penal) y se despliega en dos sentidos.

En primer lugar, introduce en el art. 2.2 de la DM OEDE 32 categorías delictivas excluidas del control de doble tipificación, trascendental innovación no exenta de controversia. Surgieron dudas relativas a la preservación de los principios de legalidad de delitos y penas, igualdad y no discriminación,

18 Acto del Consejo de 27 de septiembre de 1996 por el que se establece el Convenio relativo a la extradición entre los Estados miembros de la Unión Europea (DO C 313, de 23 de octubre de 1996, p.11).

19 Propuesta de decisión marco del Consejo sobre el mandamiento de detención europeo y los procedimientos de entrega entre Estados miembros presentada por la Comisión en Bruselas el 19 de septiembre de 2001 [COM (2001) 522 final]. 
dudas que despejara el TJUE en la sentencia dictada en el asunto Advocaten vor deer Wereld $^{20}$, que declaró su compatibilidad con el art. 6.2 del TUE. ${ }^{21}$ De otro lado, autores como Barbe (2006: 199) lanzaron la pregunta, aún no respondida, de si tal técnica legislativa no sería contraproducente para la armonización legislativa.

En segundo término, relega la ausencia de doble tipificación a motivo opcional de rechazo. Con ello, se invierte el paradigma, como hace notar Sánchez Legido (2007: 22), pasando a ser regla general la irrelevancia de la tipificación de la conducta en el Estado de ejecución en cuanto a las 32 categorías delictivas contempladas en el art. 2.2 de la DM OEDE y constituyendo la falta de correspondencia en cuanto a la tipicidad de unos determinados hechos un motivo de denegación facultativo a valorar en cada caso.

Como acontece en otros aspectos de la OEDE, no debemos precipitarnos a conclusiones expansivas que pudieran resultar algo lejanas de la realidad. Veamos cómo opera en la práctica la doble incriminación tanto en la DM OEDE como en los ordenamientos nacionales.

\section{LOS ARTS. 2.4 Y 4.1 DE LA DECISIÓN MARCO OEDE. SU TRANSPOSICIÓN ${ }^{22}$}

Para las infracciones no incluidas en su art. 2.2, el art. 2.4 de la DM OEDE establece que «la entrega podrá supeditarse al requisito de que los hechos que justifiquen la emisión de la orden de detención europea sean constitutivos de un delito respecto del Derecho del Estado miembro de ejecución, con independencia de los elementos constitutivos o la calificación del mismo». Y, por su parte, el art. 4.1 consagra como motivo de denegación facultativa de la entrega el supuesto de que en alguno de los casos del art. 2.4 de la DM OEDE «los hechos que motiven la orden de detención europea no fueren constitutivos de delito de acuerdo con el Derecho del Estado miembro de ejecución», quedando al margen la materia impositiva, en la que no podrá invocarse esta causa por la falta de gravamen de los mismos hechos con tasas o impuestos en el Estado de ejecución.

20 Sentencia de 3 de mayo de 2007, Advocaten voor de Wereld VZW v. Leden van de Ministerraad, C-305/05, EU:C:2007:261. Para un comentario detallado de la misma véase Acosta Sánchez (2007:959-973).

21 Versión consolidada del Tratado de la Unión Europea, de 7 de febrero de 1992 (DO C 326, de 26 de octubre de 2012, p. 13).

22 Para una panorámica completa de transposición de la DM OEDE véase Fichera (2011) 
El problema surge por la transposición en muchos Estados miembros de un motivo de denegación originariamente facultativo como motivo obligatorio. Compartimos las posiciones contrarias a esta técnica legislativa, llegando Grandi y Bernardi (2006: 274) a calificarla de imprecisa e ilegítima en relación con la transposición por algunos Estados miembros del art. 4.4 DM OEDE. También Klimek (2016: 8-9) critica la heterogeneidad creada, haciéndose eco de la preocupación de la Comisión al respecto. Otros autores extienden su crítica a modalidades de transposición que van más allá, articulando motivos de denegación no expresamente contemplados en la DM OEDE; así Aguilera Morales (2011: 18) respecto de Dinamarca, Países Bajos, Malta, Portugal y Reino Unido.

Resulta muy interesante la posición del abogado general en el asunto Tupikas $^{23}$, en relación con el art. 4 bis de la DM OEDE, al afirmar que la legislación nacional «revierte la lógica de la Decisión Marco al transformar la 'posibilidad de no ejecutar salvo si concurren los supuestos a) a d) en una obligación de no ejecutar a menos que se dé uno de los supuestos a) a d)». En los puntos 76 a 79 concluye que la OWL ${ }^{24}$, o ley de transposición al derecho neerlandés, de la DM OEDE ha «transformado la lista de las cuatro excepciones a la posibilidad de no ejecutar la ODE cuando el interesado no ha comparecido en el juicio del que derive la resolución en una lista taxativa de situaciones en las que la autoridad de ejecución puede ejecutar la ODE únicamente si el interesado no ha comparecido personalmente en el procedimiento». Con ello, según el abogado general, se priva a las autoridades judiciales de ejecución de margen de apreciación para ponderar todas las circunstancias concurrentes, siendo ello contrario a la doctrina del TJUE sobre el art. 4.6 DM OEDE expresada en los asuntos Poplawski ${ }^{25}$ y Dworzecki. ${ }^{26}$

No obstante, la realidad muestra lo frecuente de esta técnica de transposición, de la que ofrecemos tres ejemplos, entre otros muchos existentes. En el Reino Unido, las secciones 64(3)(b) y 65(3)(b) de la Ley sobre Extradición ${ }^{27}$ formulan como condición para la extradición en el contexto de la OEDE,

23 Conclusiones del abogado general Bobek, presentadas el 26 de julio de 2017, Tupikas, C-270/17 PPU, EU:C:2017:609, punto 75.

24 Overleveringswet, de 29 de abril de 2004. Disponible en: https://zoek.officielebekendmakingen.nl/.

25 Sentencia de 29 de junio de 2017, Popławski, C-579/15, EU:C:2017:503, apdos. 21 a 23.

26 Sentencia de 24 de mayo de 2016, Dworzecki, C-108/16 PPU, EU:C:2016:346, apdos. 50 a 52.

27 Extradition Act 2003, Chapter 41. Disponible en https:/www.legislation.gov.uk/ ukpga/2003/41/contents. 
tanto para enjuiciamiento como para ejecución de sentencia, que la conducta hubiera constituido delito si se hubiera cometido en el Reino Unido.

En Francia, el art. 695-23 del Código Procesal Penal ${ }^{28}$ introducido por la Ley 2004-204, de 9 de marzo de 2004, dispone que, salvo los delitos comprendidos en las 32 categorías del art. 2.2 de la DM OEDE, se denegará la entrega si el hecho que origina la petición de extradición no constituye una infracción conforme a la ley francesa.

En Alemania, la Ley de Cooperación Internacional en Materia Penal, ${ }^{29}$ en su art. 3.1, requiere para la extradición que el delito sea también un acto contrario a la ley alemana o, mutatis mutandis, que el delito pudiera constituir también un delito en Alemania. Estableciéndose en su parte VIII, dedicada a la extradición y tránsito entre Estados miembros de la UE, art. 81, unos requisitos complementarios de punibilidad alineados con los previstos en la DM OEDE y llevándose a cabo una transposición literal de los arts. 2.2 y 4.1, inciso segundo, de la DM.

En cambio, en España la transposición sigue la letra de la DM OEDE y no eleva a obligatoria la causa facultativa de denegación de la entrega. El art. 20 de la Ley de Reconocimiento Mutuo de Resoluciones Penales en la Unión Europea $^{30}$ (LRM) excluye del control de doble tipificación las infracciones del art. 2.2 DM OEDE y para el resto, excepción hecha de la materia tributaria, aduanera y de control de cambios, en su núm. 4. prevé que «cuando la orden o resolución judicial que se reciba castigue un hecho tipificado como un delito distinto de los previstos en este artículo, su reconocimiento y ejecución podrán supeditarse al cumplimiento del requisito de la doble tipificación», y en el mismo sentido su art. 32.2.

Nuestro Tribunal Constitucional (TC) se ha mostrado además especialmente escrupuloso respecto del margen de discrecionalidad que la DM y la ley de transposición de la OEDE conceden al juez. En la sentencia 191/200931 analizó el problema que se planteaba con la redacción del art. 12.2 de la anterior

28 Code de Procédure Pénale. Disponible en: https://bit.ly/2J2xdXy.

29 Gesetz über die internationale Rechtshilfe in Strafsachen in der Fassung der Bekanntmachung vom 27. Juni 1994 (BGBl. I S. 1537), das zuletzt durch Artikel 3 des Gesetzes vom 27. August 2017 (BGBl. I S. 3295) geändert worden ist. Disponible en: https://bit. ly/2J1gvi6.

30 Ley 23/2014, de 20 de noviembre, de reconocimiento mutuo de resoluciones penales en la Unión Europea (BOE 282, de 21 de noviembre de 2014, p. 95437)

31 Sentencia 191/2009, de 28 de septiembre de 2009 (BOE 254, de 21 de octubre de 2009, p. 17) ES:TC:2009:191. 
ley de transposición ${ }^{32}$, y que se reproduce en la actual LRM, que tampoco contiene parámetros interpretativos de aplicación de las causas de denegación facultativas, lo cual según el TC no exime de motivar reforzadamente la decisión, especialmente cuando se accede a la entrega.

\section{JURISPRUDENCIA DEL TJUE A PROPÓSITO DE LA INTERPRETACIÓN DEL PRINCIPIO DE DOBLE INCRIMINACIÓN}

La producción del TJUE en relación con el reconocimiento mutuo en materia criminal no es copiosa; tampoco es elevado el número de resoluciones relativas a la DM OEDE. ${ }^{33}$ Sin embargo, una serie de resoluciones del TJUE pueden ayudarnos a conformar un marco de referencia hermenéutico para los arts. 2.4 y 4.1 de la DM OEDE:

a) La sentencia del asunto Pupino ${ }^{34}$ relativa a la interpretación conforme del derecho nacional, y sin quebranto de este, con la normativa supranacional de referencia, su espíritu y finalidad. A la luz de esta doctrina, la exégesis de los preceptos de la legislación de un Estado miembro transponiendo los arts. 2.4 y 4.1 de la DM OEDE deben interpretarse de manera consistente con la DM. Sin embargo, este enunciado requiere que no se entre en colisión con la norma nacional, por lo que si un Estado miembro ha transpuesto la DM configurando como causa de denegación obligatoria lo que esta instauró como facultativa, la virtualidad de la doctrina Pupino es muy escasa.

b) La necesidad de interpretación restrictiva de las causas de denegación se repite como en la producción del TJUE. Así, en Wolzenburg ${ }^{35}$, apdos. 57 y 58, el Tribunal, recuerda las limitadas posibilidades de denegación de una solicitud de entrega — como subraya Marguery (2011)—, remitiéndose a la literalidad de los arts. 3 y 4 de la DM OEDE. Esto es una constante del TJUE ${ }^{36}$, recordando que incluso los motivos facultativos podrían ser reducidos por los Estados miembros sirviendo mejor al

32 Ley 3/2003, de 14 de marzo, sobre la Orden Europea de Detención y Esntrega (BOE 65, de 17 de marzo de 2003, p. 10244)

33 Eurojust, Case law by the Court of Justice of the EU on the European Arrest Warrant, (2017). Disponible en: https://bit.ly/2AcEq4P.

34 Sentencia de 16 de junio de 2005, Pupino, C-105/03, EU:C:2005:386.

35 Sentencia de 6 de octubre de 2009, Wolzenburg, C-123/08, EU:C:2009:616.

36 Sentencias de 17 de julio de 2008, Kozlowski, C-66/08, EU:C:2008:437, y de 29 de enero de 2013, Radu, C-396/11, EU:C:2013:39, entre otras muchas. 
principio de reconocimiento mutuo, del que por otra parte no contamos con una definición (Klip, 2016: 362).

c) En la misma línea de interpretación restrictiva de las excepciones a la regla general de reconocimiento y ejecución, la sentencia dictada en el asunto Grundza $^{37}$, en la que el TJUE estudia los arts. 7.3 y 9.1 d) de la DM 2008/909 sobre traslado de personas condenadas, pero de forma que resulta absolutamente aplicable a la DM OEDE. El TJUE aborda la cuestión de la doble incriminación, constituyendo el referente de mayor importancia en la materia, del que destacamos:

- El art. 7.3 de la DM 2008/909, trasunto del art. 4.1 de la DM OEDE, «permite al Estado de ejecución supeditar el reconocimiento de la sentencia y la ejecución de la condena al cumplimiento del criterio de la doble tipificación» (apdo. 28). Personalmente, interpretamos que esta afirmación avala de forma expresa la viabilidad de la técnica de transposición que configura como obligatoria lo que en la DM es una causa facultativa de denegación.

- Los apdos. 33 a 36 trazan las líneas generales de comprensión del problema, estableciendo una serie de criterios básicos. Primero, corresponde a la autoridad judicial de ejecución comprobar si los hechos por los que se reclama a una persona constituyen una infracción conforme a su derecho nacional con independencia de sus elementos constitutivos o de su calificación. Segundo, no es necesario, para que el juicio de comparación ofrezca un resultado positivo, que se trate de infracciones idénticas en ambos Estados. No es necesaria una coincidencia exacta entre los elementos constitutivos del delito, tal como se definen en la legislación del Estado de emisión y del Estado de ejecución, o entre el nombre dado o la calificación del delito en virtud del derecho nacional de los Estados respectivos (apdo. 35). Tercero, debe tenerse en cuenta la redacción, contexto y objetivo de la DM y todos estos factores recomiendan un enfoque flexible de las autoridades competentes al evaluar la condición de doble incriminación. Y cuarto, los factores relevantes son los relativos a la congruencia de los elementos de hecho subyacentes al delito, reflejados en la sentencia dictada en el Estado de emisión y la definición de la infracción en la legislación del Estado de ejecución.

De la lectura de esta sentencia parece seguirse, y así lo sostenemos, que a la luz del texto de la DM 2008/909 (valga decir sus correspondientes

37 Sentencia de 11 de enero de 2017, Grundza, C-289/15, EU:C:2017:4. 
arts. 2.4 y 4.1 DM OEDE) no es suficiente que el hecho que se tipifica como delito en el Estado de emisión y por el que se solicita la entrega pueda constituir cualquier delito en el Estado de ejecución. Será necesario que la configuración típica de la conducta en este último guarde cierta analogía, aunque no identidad, con la del Estado de emisión. En este sentido interpretamos la redacción del art. 2.4 DM OEDE, «con independencia de los elementos constitutivos o la calificación del mismo». Se podría sostener que la literalidad de la DM OEDE sugiere que cualquiera que fuese la posibilidad de subsunción de los hechos en el Estado de ejecución, con tal de que existiese un "eco típico» para la misma conducta, ello sería bastante para no denegar la entrega, mas no compartimos tal hipótesis. Este no parece el criterio más lógico de interpretación, ya que podría desconectar completamente en términos de gravedad, y por ende de proporcionalidad, la infracción por la que se reclamase a una persona con su correspondencia en el Estado de ejecución (aunque ello está admitido por el auto del TJUE dictado en el asunto $A$., al que luego nos referiremos). Pero, lo que es más importante, podría desconectar en términos ontológicos ambas infracciones de manera que la tipicidad de los hechos en el Estado de ejecución podría jugar un papel más o menos aleatorio. Ello pugnaría con la vinculación entre doble criminalidad y legalidad penal, con la unidad o similitud de designio incriminatorio, que es el fundamento de la doble incriminación (Plachta, 2003: 185-186) que la DM OEDE permite mantener como motivo facultativo de denegación, y que Falkiewicz (2018: 273) considera igual para todo tipo de cooperación. No obstante, será la legislación de transposición de cada Estado y su jurisprudencia nacional los que determinen cómo se interpreta en ellos la necesaria correspondencia.

La cuestión dista de estar clara, puesto que los contornos de ese determinado grado de homología que estimamos necesaria resultan harto difusos, como tendremos ocasión de exponer más abajo.

- Concluye la sentencia Grundza que el requisito de doble incriminación como excepción a la regla general de reconocimiento es de interpretación restrictiva (apdo. 46) y que para apreciar su concurrencia lo esencial es verificar «si los hechos que dan lugar a la infracción, tal como fueron plasmados en la sentencia dictada por la autoridad competente del Estado de emisión, también estarían sujetos, en cuanto tales, a una sanción penal en el territorio del Estado de ejecución si se hubieran producido en dicho territorio" (apdo. 47), «no es si ha resultado lesionado el interés protegido por el 
Estado de emisión, sino [...] en el supuesto de que la infracción en cuestión se hubiera cometido en el territorio del Estado miembro al que pertenece aquella autoridad (de ejecución), se habría considerado que un interés semejante, protegido por el Derecho nacional de ese Estado, ha resultado lesionado» (apdo. 49).

d) La sentencia dictada en el asunto Grundza complementa la doctrina del TJUE en el asunto $A \cdot{ }^{38}$, en la que razona que cualquiera que sea la pena que los hechos podrían conllevar en el Estado miembro de ejecución, la ley del Estado miembro de emisión es la relevante. Para la comparación que contemplan los arts. 2.4 y 4.1 de la DM OEDE, basta que el hecho sea delito en el Estado de ejecución, cualquiera que sea la gravedad de la pena aparejada. El TJUE declara no admisible una transposición que exigiese que los hechos en el Estado de ejecución estuviesen castigados con penas de prisión de un máximo de al menos doce meses. Y precisa (apdos. 24, 25 y 27) que rechazar la extradición vía art. 4.1 de la DM OEDE requiere que los hechos por los que se reclama a la persona no sean en absoluto constitutivos de delito en el Estado de ejecución, ya que ni el art. 2.4, ni 4.1, ni ningún otro pasaje permiten establecer la citada condición de mínima punibilidad, siendo el único marco de referencia al respecto el establecido en la legislación del Estado de emisión (apdo. 30).

e) En el reciente asunto Piotrowski ${ }^{39}$, el TJUE interpreta la aplicación de la causa obligatoria de denegación de entrega de un menor de edad (art. 3.3 de la DM OEDE) de interés en cuanto a una interpretación holística de los motivos de denegación contemplados en el instrumento. Conforme al precepto mencionado, la OEDE se denegará cuando la persona reclamada «no pueda ser, por razón de su edad, considerada responsable penalmente de los hechos en que se base dicha orden, con arreglo al Derecho del Estado miembro de ejecución».

Citando los asuntos Grundza y Vilkas ${ }^{40}$, el TJUE recuerda que para interpretar una disposición del derecho de la Unión debe tenerse en cuenta no solo su tenor literal, sino también su contexto y los objetivos perseguidos por la normativa de la que forma parte. Y declara que la autoridad judicial de ejecución solo deberá comprobar si la persona reclamada tiene la edad mínima para ser considerada responsable penalmente de los hechos, sin tomar

38 Auto de 25 de septiembre de 2015, A., C-463/15PPU, EU:C:2015:634.

39 Sentencia de 23.01.18, Piotrowski, C-367/16, EU:C:2018:27.

40 Sentencia de 25 de enero de 2017, Vilkas, C-640/15, EU:C:2017:39. 
en consideración si concurren eventuales requisitos adicionales de evaluación personalizada a los que el derecho de ese Estado miembro supedite en concreto el enjuiciamiento o la condena. Las autoridades judiciales polacas solicitaban a Bélgica la entrega de una persona de diecisiete años, responsable penal como adulto en Polonia. En Bélgica existe un régimen especial entre dieciséis y dieciocho años, en el que tras estudiar la personalidad del menor y otros factores, se decide si es juzgado conforme al derecho penal común o al de menores. La duda de los jueces belgas era relativa a la apreciación, en abstracto o en concreto, de la responsabilidad del menor. Conforme a la primera existía la posibilidad en abstracto de que el menor fuera considerado penalmente responsable; conforme a la segunda habría que evaluar una serie de factores muy complicados y solo si la respuesta es positiva, proceder a la entrega. La respuesta del TJUE es tajante a la hora de rechazar una apreciación in concreto, afirmando que la realización de un juicio de valoración antes de la entrega es contraria a la finalidad del sistema de cooperación basado en el reconocimiento mutuo (apdos. 55 y 56 de la sentencia, en línea con las conclusiones del abogado general Bot, que hace notar que este tipo de operaciones de determinación concreta de responsabilidad privaría de todo efecto útil al reconocimiento mutuo).

El contenido de esta sentencia puede mover a cierta perplejidad por el diferente trato que se da, en Grundza y en esta sentencia que ahora comentamos, a dos realidades similares: la prevista en el art. 2.4 en relación con el 4.1 de la DM OEDE, y de otro la contemplada en su art. 3.3. Afirmándose en el apdo. 55 que

no puede admitirse que determinados Estados miembros, debido a que su Derecho nacional aplica una técnica de apreciación caso por caso de la responsabilidad penal de los menores mediante la comprobación in concreto de la concurrencia concomitante de los tres criterios expuestos [...]puedan retomar este análisis en calidad de Estado miembro de ejecución. De hecho, ello equivaldría a restablecer un sistema de extradición estricto, que requiere que el Estado miembro de ejecución reciba el expediente completo de las diligencias penales incoadas o de la condena y verifique que corresponde en todos sus elementos a los de su propio procedimiento nacional.

\section{EL ASUNTO PUIGDEMONT}

Este asunto constituye un modelo de idóneo para el estudio del principio de reconocimiento mutuo y su aplicación en relación con la doble incriminación en la DM OEDE, con independencia del sentido de su resolución final. 
El juez instructor de la causa especial seguida ante el Tribunal Supremo de España dictó auto de procesamiento contra los investigados y remitió una OEDE a Alemania, donde fuera detenido el Sr. Puigdemont, solicitando su extradición a España para ser juzgado por los delitos de rebelión (arts. 472 y concordantes del Código Penal) ${ }^{41}$ y malversación de caudales públicos (art. 432 en relación con el 252 de la misma ley).

El Schleswig-Holsteinisches Oberlandesgericht (Tribunal Regional Superior de Schleswig-Holstein), en resolución de 5 de abril de 2018,42 esencialmente ratificada por otra de 12 de julio de 2018, tras afirmar la corrección de lo actuado por la policía, la Fiscalía y el Tribunal de Primera Instancia, abordaba la cuestión de la situación personal del reclamado por España. El art. 15 de la Ley de Cooperación Internacional en Materia Penal (IRG) ordena el mantenimiento en prisión preventiva del reclamado a no ser que la petición de entrega se revelase ab initio como inviable. Aplicando tal norma, concluye que, respecto del delito de rebelión, la extradición debe considerarse inadmisible en principio. En cambio, respecto del delito de malversación de caudales públicos (variante del delito de corrupción) se dejaba abierta tal posibilidad, bien que con ciertos condicionantes. Tras rechazar cualquier tipo de persecución política en relación con el reclamado, establecía fianza para que pudiera eludir la prisión preventiva, conforme a la IRG y al propio art. 12 de la DM OEDE, durante la tramitación del caso ${ }^{43}$, al tiempo que abría la posibilidad a la Fiscalía para que, al amparo del art. 30.1 de la IRG, solicitase al Tribunal Supremo español información adicional sobre el delito de malversación.

El análisis realizado por el Tribunal de Schleswig-Holstein puede sintetizarse como sigue:

a) El delito de rebelión no se encuentra en la lista del art. 2.2 de la DM OEDE (art. 81 de la IRG). Por lo tanto, se requiere, conforme a los arts. 3.1 y 81.4 contrario sensu de la IRG, verificar que los hechos por los que se reclama al ciudadano español serían constitutivos de delito en Alemania.

Para realizar esta comprobación, se remite a la conversión análoga, pauta del art. 3.1 de la IRG: es decir, que, mutatis mutandis, el delito pudiera constituir también un delito en Alemania, en línea con el art. 2.4 de la DM

41 Ley Orgánica 10/1995, de 23 de noviembre, del Código Penal (BOE 281, de 24 de noviembre de 1995 , p. 33987).

42 Orden del Tribunal Superior regional de Schleswig-Holstein. Sección Primera Penal. Asunto 1 Ausl (A) 18/18 (20/18), DE:OLGSH:2018:0405.1AUSL.A18.18.20.1.00.

43 Respecto de la adopción de medidas cautelares personales en este contexto véase Jimeno Bulnes (2005, 119-122). 
OEDE, que habilita para hechos no incluidos en su art. 2.2 que la entrega pueda supeditarse a que estos sean constitutivos de un delito en el Estado de ejecución, «con independencia de los elementos constitutivos o la calificación del mismo».

A continuación, razona que los arts. 81 y 82 del Código Penal alemán (StGB), que tipifican la alta traición contra la Federación o contra un Estado de la misma, no resultarían aplicables en este supuesto, puesto que la doctrina de la misma Sala, que cita, requiere que los hechos resulten comparables en lo fundamental y además una suerte de exégesis locativa, imaginando los hechos como acontecidos en Alemania, realizados por un autor ciudadano alemán y con posible afectación para instituciones alemanas. Este requisito se estudia a su vez a la luz de la jurisprudencia del Bundesgerichtshof (Tribunal Federal alemán) sobre el delito de alta traición y la violencia necesaria para su apreciación, todo ello con motivo de unos incidentes acaecidos en el aeropuerto de Frankfurt en $1983 .{ }^{44}$

Admitiendo que la redacción del art. 81 del Código Penal alemán: «Quien pretenda poner en peligro con violencia o amenaza de violencia la existencia de la RFA» pudiera ser equiparable al tipo de rebelión español, y que «es innegable que un referéndum pensado para conducir a la independencia a una región de un estado se correspondería con el designio de poner el peligro la existencia del Estado", declara el Tribunal, siguiendo al Tribunal Federal, que no concurre la violencia necesaria para llenar el tipo, puesto que la que se produjo no fue de tal entidad como para suponer una amenaza real de doblegar la voluntad del Gobierno.

b) Por lo que hace al delito de malversación, la conducta se califica en la OEDE recibida bajo el epígrafe de corrupción, ilícito encuadrado en la lista del art. 2.2 de la DM OEDE, lo que excluiría del control de doble tipificación. No obstante, se hacía notar un déficit en la información aportada que no llenaría las exigencias del art. 83a (1) 5 de la IRG en cuanto a la descripción de las circunstancias en que se produjeron los hechos y a los datos que permitan atribuir el delito al comportamiento del reclamado. Por ello se abrió la posibilidad a la Fiscalía para recabar de la autoridad de emisión información suplementaria conforme la art. 30.1 de la IRG.

c) Esta decisión, así como la de cierre del procedimiento extradicional, dictada por el mismo Tribunal el 12 de julio de 2018 conforme al art. 32 de la IRG, que concede la extradición del Sr. Puigdemont solo por el delito de

44 Sentencia del Tribunal Federal, $3^{\text {a }}$ sala penal del 23 de noviembre de 1983, 3 StR 256/83. Disponible en: https://bit.ly/2yH03bf. 
malversación, asumiendo el análisis realizado en primera instancia, constituyen un exponente de alguno de los puntos controvertidos del sistema.

Concurren en las mismas varios factores que debilitan la pujanza del principio de reconocimiento mutuo. Así:

- La técnica de transposición empleada en Alemania convierte el motivo facultativo de denegación del art. 4.1 en relación con el art. 2.4 de la DM OEDE en motivo obligatorio en los arts. 3. y 81 de la IRG, con los inconvenientes antes descritos.

- Propugnan una interpretación próxima a lo que De Bondt refiere como doble criminalidad reforzada, que hace bascular la lógica hermenéutica de verificación de la doble incriminación sobre una aproximación nacional a la categorización del hecho por el que se reclama la extradición y a sus consecuencias. No basta con que este sea delito en el Estado de emisión, ni que la ley alemana prevea tipos similares, o tutele el mismo o parecidos bienes jurídicos; es necesario, por el contrario, imaginar que, aconteciendo los hechos en Alemania, con los mismos actores y circunstancias, también habrían sido delito. Ciertamente, la doctrina de la sentencia dictada en el asunto Grundza avala la regularidad de esta opción interpretativa al sancionar esta vía de comparación en sus apdos. 47 y 49. Pero tampoco podemos desconocer que la misma sentencia, en sus apdos. 33 a 35, enseña cuál debe ser la pauta de interpretación del art. 7.3 de la DM 909/08, y de la cláusula de que la entrega podrá supeditarse a que los hechos también sean delito en el Estado de ejecución "con independencia de los elementos constitutivos o la calificación del mismo». El TJUE interpreta esta disposición como una oportunidad para encajar tipos parcialmente dispares, para reconocer la similitud esencial más allá del nomen iuris, sin que se necesario que las infracciones sean idénticas en ambos Estados (apdo. 34), no requiriéndose «una correspondencia exacta ni entre los elementos constitutivos de la infracción, según su calificación respectiva en el Derecho del Estado de emisión y del Estado de ejecución, ni en la denominación o la clasificación de la referida infracción según los Derechos nacionales respectivos» (apdo. 35), debiendo ser flexible la apreciación del requisito de doble tipificación, tanto en lo concerniente a los elementos constitutivos de la infracción como a la calificación de ésta (apdo. 36). La doctrina Grundza parece dejar abierta una puerta tanto a la interpretación in abstracto como in concreto del requisito de doble incriminación, aunque decantándose finalmente por un enfoque más concreto derivado del mecanismo de comparación que propugna. Aun así, coincidimos con Falkiewicz (2018: 266) en que la interpretación in abstracto es la que mejor satisface al principio de 
reconocimiento mutuo, en tanto que la interpretación in concreto podría forzar a la autoridad de ejecución a realizar un análisis detallado de los hechos, que puede no ser posible en un momento inicial como es la petición de entrega para enjuiciamiento.

- Todo lo anterior sitúa a una extradición solicitada por España de acuerdo con la DM OEDE, en cuanto a la verificación de la doble incriminación, de facto exactamente al mismo nivel que una extradición solicitada por un Estado que no pertenezca a la Unión Europea, debiéndose comprobar el requisito de la doble tipificación de manera exhaustiva y en cierto modo desligada de la idea de confianza que preside la cooperación basada en el reconocimiento mutuo.

d) La valoración que por dos veces realiza el tribunal alemán de la no existencia de violencia bastante o capacidad compulsiva que justificare la rebelión conforme a su derecho pertenece a la ley y a la jurisprudencia alemanas, con lo que desborda el ámbito de nuestro comentario. Aunque ha sido objeto de crítica —entre otros, por Gimbernat Ordeig (2018)_, creemos que la interpretación de la IRG corresponde a los tribunales alemanes y estos deben decidir si la extradición procede conforme a la misma, aunque no compartamos íntegramente lo resuelto. También usa el tribunal de sus facultades de interpretación de la ley nacional alemana, al recurrir al ejemplo de la revuelta en el aeropuerto de Frankfurt o para la comparación con el delito de alta traición del art. 81 del Código Penal alemán.

La ponderación respecto de la doble incriminación se basa en un estudio de la legislación nacional por el Tribunal de Schleswig-Holstein que no estamos en disposición de cuestionar, aun discrepando de la decisión puesto que existen tipos relativos a preparación de la traición, desobediencia, resistencia, revueltas y otros que podrían sugerir coincidencias, al menos parciales, con el delito de rebelión español, y en consecuencia tener por cumplido el requisito de la doble incriminación en los términos que hemos visto más arriba. ${ }^{45}$

En este sentido, traemos a colación la posición del abogado general Szpunar expresada en el asunto $A Y^{46}$, sobre el que hemos de volver más adelante. En el apdo. 32 de su opinión se consigna lo siguiente:

Lo fundamental es, sobre todo, que el Estado miembro de ejecución confíe en la actuación del Estado miembro de emisión. Sin embargo, también el Estado miembro

45 Código Penal alemán, arts. 83, 86, 86a, 98a, 90a , 111, 113, 125.

46 Conclusiones del abogado general, de 16 de mayo de 2018, asunto AY, C-268/17, EU:C:2018:317. 
emisor debe confiar en la actuación del Estado miembro de ejecución cuando este último invoca algún motivo de denegación de la ejecución de una ODE. Una vez que el Estado miembro emisor empieza a aplicar y a interpretar la legislación del Estado miembro de ejecución y trata de verificar si este último ha aplicado correctamente la ley, comienza a acercarse peligrosamente al punto de ruptura de esta confianza mutua.

Tampoco coincidimos con el análisis que se ha hecho respecto de lo inoportuno de un rechazo ad limine del delito de rebelión (Mangas Martín, 2018); creemos por el contrario que conforme a la legislación alemana resultaba tempestivo valorar la existencia de un delito equiparable al de rebelión en Alemania. Otra cosa es que el tribunal tuviese dudas y hubiese de diferir su decisión a un momento ulterior tras recabar la oportuna información complementaria al amparo de la doctrina sentada por el TJUE en Aranyosi-Caldararu (Sarmiento: 2018). Quizás, como hipótesis, hubiera sido de interés ampliar el plano de análisis, llevando al límite las posibilidades interpretativas de los apdos. 47 y 49 de la sentencia Grundza. En este supuesto singular se pide la extradición por el Tribunal Supremo de un Estado miembro por un delito de rebelión que en última instancia atentaría no solo contra la Constitución e integridad territorial de España, sino que afectaría al orden constitucional ${ }^{47}$ y la integridad de la propia Unión, de la que quedaría automáticamente desgajada una región que se independizase de un Estado miembro (Mangas Martín: 2013). No creemos que ello justificara, per se, un apartamiento ad hominem de la línea de interpretación de esta materia por los tribunales alemanes, lo cual incluso podría entrar en conflicto con la jurisprudencia del Tribunal Europeo de Derechos Humanos fijada en el asunto Del Río Prada ${ }^{48}$. Pero sí nos permitimos subrayar que sería muy deseable una intensa dosis de equidad para abordar la OEDE relativa a un delito que ataca al Estado de derecho (art. 1 bis del TUE), siendo competente para su conocimiento el Estado miembro de emisión (art. 3 bis del TUE), como recuerdan las conclusiones del Consejo de la Unión Europea de 16 de diciembre de $2014 .{ }^{49}$

47 Sobre la propia existencia del orden constitucional europeo, véase Fich et al. (2012: 151-195).

48 Sentencia de 21 de octubre de 2013, Del Río Prada c. España [GC], núm. 42750/09, CE:ECHR:2013:1021JUD004275009.

49 Conclusiones del Consejo de la Unión Europea y los Estados miembros reunidos en el Consejo garantizar el respeto del Estado de derecho, Reunión del Consejo de Asuntos Generales, Bruselas, 16 de diciembre de 2014. Disponible en https://bit. ly/2yKHL9o. 
e) Las opciones procesales abiertas tras el rechazo no resultan demasiado halagüeñas.

- La primera se intentó tras la reunión de coordinación habida el 12 de abril de 2018 en la sede de Eurojust, de la que se hace eco la prensa ${ }^{50}$ aunque no aparece en las notas de prensa de la institución. ${ }^{51}$ El 26 de abril se remitió por el Tribunal Supremo un oficio ampliatorio con nuevos datos, aclaraciones y evidencias, entre ellas 74 vídeos anexos, relativas tanto al delito de malversación de caudales como al de rebelión, abriendo incluso la posibilidad de extraditar al Sr. Puigdemont por un delito de sedición.

Con fecha 1 de junio de 2018, la Fiscalía ante el Tribunal Superior de Schleswig-Holstein reiteró la petición de extradición del Sr. Puigdemont por los delitos de malversación y rebelión ${ }^{52}$, tras recibir documentación complementaria por parte de las autoridades españolas que permitía mantener su apreciación inicial y concluir que: los requisitos de doble incriminación se cumplen en relación con los delitos de rebelión y malversación (que subsume dentro de la corrupción, incluida en el art. 2,2 DM OEDE); que existe una correspondencia entre el delito de rebelión español y el de alta traición del art. 81 del Código Penal alemán, y que el Tribunal se había extralimitado al entrar a valorar el fondo del asunto.

No obstante, la decisión final adoptada el 12 de julio de 2018 por el Tribunal Regional de Schleswig-Holstein, de conformidad con el art. 33 de la IRG, ha ratificado lo resuelto en primera instancia por el mismo Tribunal en abril y concede la extradición del reclamado solo por el delito de malversación.

- En cuanto a la posibilidad de elevar una cuestión prejudicial por el magistrado instructor del Tribunal Supremo al TJUE, que dilataría sustancialmente la tramitación de la causa, se nos antoja un tanto inconsistente con la esencia de los arts. 267 del TFUE y 19.3 b) del TUE ${ }^{53}$. La premisa de tal mecanismo es que el juez o tribunal que conozca de un asunto considere que las respuestas del TJUE «sobre la interpretación de los tratados o sobre la validez e interpretación de los actos adoptados por las instituciones, órganos u organismos de la Unión» —apdos. a) y b) del

50 Véanse, entre otros, Reuters, 11-4-2018, disponible en: https://bit.ly/2ysKgOj, o El País, 12-4-2018, disponible en: https://bit.ly/2v6fNWR.

51 Eurojust Press Centre, Press releases. Disponible en: https://bit.ly/2IYzdA7.

52 El Pais, 1-6-2018, disponible en: https://bit.ly/2PBiLsh.

53 Sobre la cuestión prejudicial en general, véase Vandersanden (2013). 
art. 267 del TFUE — resulte necesaria para poder emitir su fallo. Y en el mismo sentido las recomendaciones del TJUE al respecto, apdos. 5, 12, 15,16 y $24 . .^{54}$

En la situación que examinamos, un pronunciamiento del TJUE relativo a los arts. 2.4 y 41 de la DM OEDE no resulta necesario para que el instructor resuelva lo que estime oportuno, en todo caso lo sería para el tribunal alemán antes de resolver sobre la extradición. Lo resuelto por el TJUE tendría diferente trascendencia, como expone Ripoll Carulla (2014: 47), dependiendo del tipo de cuestión. Una cuestión sobre interpretación planteada por el instructor del Tribunal Supremo vincularía a este con fuerza de cosa juzgada, asunto $M_{i l c h}{ }^{55}$, y a otros órganos judiciales españoles llamados a conocer del mismo procedimiento. También obligaría, con carácter general, a los órganos jurisdiccionales de otros Estados miembros (Schermers, 1983: 362 y ss.), pero resultaría en extremo complejo pretender que tal vinculación opere en relación con una decisión ya tomada por las autoridades de otro Estado (Cobreros Mendazona, 2014: 127-141).

Particularmente interesante al respecto es la opinión del abogado general en el asunto $A Y$ anteriormente citado. El Tribunal del Condado de Zagreb, Croacia, expuso al TJUE el caso del ciudadano húngaro $A Y$ reclamado en 2013 y 2015 a Hungría por OEDE, que no fue entregado puesto que Hungría abrió procedimiento penal sobre los mismos hechos, en el que $A Y$ declaró como testigo, que posteriormente sobreseyó. En este contexto el Tribunal de Zagreb pregunta al TJUE respecto de la denegación de entrega por las autoridades judiciales húngaras. El abogado general razona que lo resuelto por el TJUE no afectaría a la autoridad de emisión que consulta: «Este hecho resulta un tanto extraño, pues la respuesta del Tribunal de Justicia solo afectaría a las autoridades de ejecución» (punto 20). Luego, puntos 21 a 34, estudia la competencia del TJUE para contestar a las cuestiones planteadas. Analizando el art. 267 del TFUE, afirma que «es competente para dictar una decisión prejudicial cuando el tribunal remitente estime que una decisión sobre la cuestión prejudicial planteada es 'necesaria' para poder emitir su fallo...En un asunto como el presente, soy totalmente incapaz de ver la necesidad

54 Recomendaciones del Tribunal de Justicia de la Unión Europea a los órganos jurisdiccionales nacionales, relativas al planteamiento de cuestiones prejudiciales. (DO C 257, de 20 de julio de 2018, p. 1).

55 Sentencia de 24 de junio de 1969, Milch-, Fett- und Eierkontor, C-29/68, EU:C:1969:27. 
de una respuesta del Tribunal de Justicia para el procedimiento ante el tribunal remitente» (puntos 25 y 26). Y en el 32, que el mecanismo contempla que "los tribunales nacionales comunican los hechos y ofrecen una descripción del Derecho nacional [...] a fin de permitir que el Tribunal de Justicia ofrezca una interpretación útil y finalista del Derecho de la Unión...esto solo puede garantizarse si el tribunal remitente se halla efectivamente en condiciones de aplicar la interpretación del Tribunal de Justicia al asunto que se discute».

Sin embargo, la tesis del abogado general (seguida por el instructor del Tribunal Supremo en su auto de 19 de julio de $2018^{56}$, que rechaza la entrega del Sr. Puigdemont solo por malversación y retira la euroorden) no es seguida por el TJUE en su sentencia ${ }^{57}$. En una decisión, que personalmente no compartimos, el TJUE razona que resulta pertinente el planteamiento de la cuestión, siendo de interpretación restrictiva la negativa del Tribunal a pronunciarse, y concurriendo el presupuesto ontológico del planteamiento como es la disyuntiva para el órgano judicial remitente de retirar la OEDE o no (apdos. 24 a 27).

- Al concederse por Alemania la entrega solo por el delito de malversación se abría una alternativa: o juzgar al Sr. Puigdemont únicamente por este ilícito o retirar la OEDE. La primera de tales opciones generaría un conflicto lógico-jurídico notable ya que otras personas, con rango inferior al del expresidente de la comunidad autónoma, se enfrentarían a cargos más graves que este derivados de la participación en los mismos hechos, en los que correspondía al presidente una posición preeminente por su carácter de máxima autoridad dentro del ejecutivo regional. La segunda vía, aún no expresamente prevista en la DM OEDE, ya había sido utilizada por el instructor del Tribunal Supremo respecto de la remitida a Bélgica por el Juzgado Central de Instrucción en su auto de 5 de diciembre de $2017^{58}$, con base en el art. 11 de la LRM. Ahora vuelve a recurrir a ella en el auto antes citado de 19 de julio de 2018 ante la denegación parcial de la entrega. Esta solución reproduce el problema que con este auto de diciembre se trató de evitar, la división de la continencia de la causa, puesto que imposibilita el enjuiciamiento conjunto de los procesados. Además, una vez concedida la entrega por malversación, retirar la OEDE coloca a la autoridad judicial española en una difícil tesitura respecto de la que podríamos cuestionar la ortodoxia jurídica. La situación

56 Auto de 12 de julio de 2018, causa especial 20917/17, ES:TS:2018:8477A.

57 Sentencia de 25 de julio de 2018, AY, C-268/17, EU:C:2018:602.

58 Auto de 5 de diciembre de 2017, causa especial 20917/17, ES:TS:2017:11325A. 
subsiguiente ofrecería la opción de aguardar a que la persona o persona reclamada se encontrase en otro Estado de la Unión, más proclive a sintonizar con los postulados de la autoridad española, y entonces reexpedir la OEDE; o bien desistir definitivamente de la misma. Una vez que se retiró la OEDE remitida a Bélgica, retirar ahora también la emitida a Alemania no nos parece aconsejable, ni tampoco desistir de la posibilidad de extraditar a los reclamados.

La cuestión del forum shopping en materia penal (Janssens, 2013: 230233; Luchtman, 2013: 3-61) pudo suscitarse, en este caso, con la primera decisión del fugado de dirigirse precisamente a Bélgica, Estado cuya ejecutoria en materia de extradición podría alentar la expectativa de que no accedería fácilmente a entregar al Sr. Puigdemont a España, señaladamente por el cargo de rebelión (Muñoz de Morales Romero, 2017). Pero una actitud por parte de la autoridad judicial de sucesivas emisiones y retiradas de una OEDE en pos del Estado miembro que finalmente conceda la extradición también por el delito de rebelión no resulta a nuestro parecer deseable en el contexto de concesión de la extradición por uno de los dos delitos.

La alternativa que consideramos más apropiada sería asumir la entrega solo por el delito de malversación, aun cuando ello conllevare la imposibilidad de juzgar al Sr. Puigdemont por rebelión (arts. 27.2 de la DM OEDE y 60 de la LRM), a no ser que ulteriormente se dieran las condiciones para ello, entre otras que una vez absuelto o liberado tras la condena cumplida no abandonara España. Con ello se conseguiría poner fin a una situación de impasse, no de forma enteramente satisfactoria, pero al menos se podría celebrar juicio contando con la presencia del principal encausado. En cambio, el auto de 19 julio de 2018, retirando no solo la OEDE relativa al Sr. Puigdemont, sino las órdenes europeas e internacionales del resto de procesados, todos ellos declarados en rebeldía mediante auto de 9 de julio de $2018^{59}$, abre un escenario realmente inquietante. La dura crítica a la resolución del tribunal alemán, que no compartimos enteramente, no plantea una reflexión sobre los problemas de compatibilidad que la calificación de los hechos como delito de rebelión presenta en el plano internacional y genera en relación con la doble incriminación en un contexto extradicional, incluso tan avanzado como la OEDE. De algún modo cierra en falso el procedimiento respecto de estos encausados; eso sí, subrayando que lo que se entiende como extralimitación en la actuación del Schleswig-Holstein Oberlandesgericht es

59 Auto de 9 de julio de 2018, causa especial 20917/17, ES:TS:2018:8089A. 
la única causante de este fracaso procedimental. No resultaba fácil, desde luego, ofrecer otra salida, especialmente si esta pasaba por asumir que los hechos habrían de forzar al instructor a mudar la calificación indiciaria de las conductas. Los acontecimientos producen estupor, ante la evidencia de la falta de sintonía del planteamiento a nivel nacional con la comprensión de los hechos en otros varios Estados y ante la cuestión de la real eficacia de la OEDE, cuando se opera con el concepto tradicional de soberanía y el control estricto de la doble incriminación (Bachmaier, 2018: 39).

- Finalmente hemos de hacer un llamado a un recurso procesal no explorado en este supuesto, cual es la posibilidad de toma de declaración e incluso de práctica de diligencias judiciales a través de una entrega temporal a España o de la realización de las mismas en territorio alemán, todo ello incluso antes de que se produzca una decisión definitiva conforme al art. 19 de la DM OEDE. Con todo, así tampoco se conseguiría ningún avance procesal de interés; existiendo una diversidad de transposiciones entre la LRM, art. 43, y la IRG, art. 83 e), que añadirían dificultades adicionales. El primero de ellos solo contempla la entrega temporal a España, mientras que el 83 e) solo prevé una petición de interrogatorio que se llevaría a cabo en Alemania. Pero ni siquiera la notificación del auto de procesamiento o la declaración conforme a lo dispuesto en los art. 385 y ss. de la Ley de Enjuiciamiento Criminal tendrían trascendencia ulterior si no se concede la entrega por uno o ambos delitos, habida cuenta de la redacción del art. 60.2 de la LRM.

f) En cuanto a la capacidad de «reacción» por parte de las autoridades judiciales españolas, el sistema OEDE es un aliud respecto de la extradición, judicializado, lo que implica un ejercicio independiente de jurisdicción, dificultando la reacción de tipo institucional. Además, no somos partidarios en ningún caso de postular una evolución de la práctica en favor de la aplicación de una política de reciprocidad respecto de Alemania, ya que ello no contribuiría sino a socavar la confianza mutua.

g) Tampoco parece realista, aparte de que no podría tener efecto retroactivo para este caso, pronosticar que el catálogo de delitos contemplado en el art. 2.2 de la DM OEDE se viera incrementado, a tenor de las declaraciones de la comisaria de Justicia Vera Jourova en diciembre de $2017^{60}$, que sugieren que la Comisión Europea no auspiciaría una iniciativa española en este sentido formulada al amparo del art. 2.3 de la DM OEDE, existiendo otras

$\overline{60}$ Véase https://euobserver.com/justice/140218. 
prioridades en cuanto a este instrumento, como se sigue de la información que refleja el sitio web de actividad legislativa del Parlamento Europeo Legislative train ${ }^{61}$.

h) Otras iniciativas (Mangas Martín, 2018) también presentan inconvenientes: la modificación legislativa que permitiese juzgar en rebeldía un mayor número de delitos no sería ya aplicable a este caso, pero de serlo tampoco solventaría, una vez juzgado el asunto y tras una hipotética condena, los problemas derivados de la doble incriminación. Y en cuanto a demandar a Alemania por incumplimiento de la DM OEDE conforme al art. 258 del TFUE, no nos parece una solución que se corresponda con la ejecutoria de las autoridades alemanas, que se encuentra respaldada por un contexto legislativo y jurisprudencial que la legitiman, en un escenario realmente apartado del Gleichstellungsprinzip, principio de equiparación o asimilación que nos describe Vogel (2001b: 177 y ss.)

\section{CONCLUSIONES}

1. La evaluación de lo sucedido requiere una comprensión mesurada y una interpretación realista de la cooperación internacional basada en el principio de reconocimiento mutuo. La virtualidad de esta no es equiparable a la de la cooperación entre órganos judiciales de un mismo Estado, ni podemos esperar una respuesta automática e incondicionada de cumplimiento. Por el contrario, existen variados motivos de denegación y condicionamiento de una solicitud de cooperación de los que la DM OEDE ofrece una muestra especialmente representativa.

2. La diversidad de modalidades de transposición por los diferentes Estados miembros de la Unión ha propiciado situaciones dispares no deseables respecto de los arts. 2.4 y 4.1 DM OEDE, transponiéndose a veces como obligatoria una causa de denegación que en la misma se contempla como facultativa, con perjuicio del reconocimiento mutuo.

3. La jurisprudencia del TJUE reitera que los instrumentos basados en el reconocimiento mutuo deben interpretarse de manera que este principio se vea favorecido, la cooperación facilitada y la libre circulación de decisiones judiciales resulte mejor servida. No obstante, las resoluciones que estudian la doble incriminación en los supuestos no incluidos en el art. 2.2 de la DM OEDE señalan que esta debe quedar satisfecha en el Estado de ejecución de

${ }^{61}$ Disponible en: https://bit.ly/2CKtuhn. 
manera que se verifique la hipótesis de que si los hechos hubiesen acontecido en su territorio estarían igualmente sujetos a sanción penal.

4. Existe un margen para la investigación hermenéutica sobre integración y compatibilización de la jurisprudencia del TJUE acerca de los motivos de denegación de la entrega cuando los hechos sean o no sean constitutivos de un delito en el Estado de ejecución, pertinencia de la comparación de infracciones in concreto o in abstracto y sobre homología y gravedad de las mismas.

5. En el supuesto que hemos estudiado, la posición del Tribunal Regional Superior de Schleswig-Holstein en la OEDE relativa al Sr. Puigdemont constituye en sí mismo un excelente ejemplo de las particularidades que la cooperación basada en el reconocimiento mutuo presenta, y ello con independencia de la resolución final del asunto de extraditar al Sr. Puigdemont solo por el delito de malversación.

6. Lo resuelto por el Tribunal Regional alemán, tanto en lo formal cuanto en lo referente a su acomodo de fondo al marco jurídico europeo, resulta esencialmente correcto y se alinea con la doctrina que emana del caso Grundza, clave de bóveda hermenéutica en tal materia.

7. Ciertamente, se podría haber interpretado, más ampliamente, de manera más dúctil y equitativa, la concurrencia de doble incriminación en este caso, pero esta tarea corresponde a la autoridad judicial de ejecución en aplicación también de su derecho y jurisprudencia nacionales. La decisión resulta conforme a derecho, aunque discrepamos de la polarizada aproximación a los hechos de los jueces alemanes al establecer la comparación de conductas e infracciones y sostenemos que otras alternativas más flexibles eran posibles.

8. Por lo que hace a las posibilidades de actuación que se abren ante la autoridad judicial española, consideramos, dentro de las que se ofrecían ante la eventualidad de una entrega solo por el delito de malversación, que la mejor decisión, aunque no óptima, sería aceptar la extradición únicamente por este cargo.

Difícil cuestión es esta, pero seguimos afirmando que el emperador, en su discurrir por el Espacio de Libertad, Seguridad y Justicia, no se encuentra desnudo al vestir el traje del reconocimiento mutuo, aunque dicho atuendo no es de seguro aquel deslumbrante y pluscuamperfecto ropaje que algunos pudieron imaginar o entender de lo que los sastres nos contaron.

\section{Bibliografía}

Acosta Sánchez, M. (2007). Tribunal de Justicia de las Comunidades Europeas. STJCE de 03.05.2007, Advocaten voor de Wereld ZWZ y Leden van Ministerradd 
C-303/05. Cooperación policial y judicial en materia penal. Orden de detención Europea. Revista de Derecho Comunitario Europeo, 28, 959-973.

Aguilera Morales, M. (2011). La orden europea de detención y entrega: regulación y balance de su aplicación en España. Revista Archivio Penale, 2, 18. Disponible en: https://bit.ly/2IDEbCm.

Alonso Moreda, N. (2017). Cooperación judicial en materia penal en la Unión Europea: "la euroorden" instrumento privilegiado de cooperación. Cizur Menor: Thomson Reuters Aranzadi.

Arroyo Zapatero, L. (2013). La armonización internacional del derecho penal. Hechos, actores y procesos en los caminos de armonización. En J. L. De la Cuesta Arzamendi, A. I. Pérez Machio y J. I. Ugartemendía Eceizabarrena (dirs.). Armonización penal en Europa. Oñati: Instituto Vasco de Administración Pública.

Bachmaier, L. (2018). Orden Europea de Detención y Entrega, doble incriminación y reconocimiento mutuo a la luz del caso Puigdemont. En L. Arroyo Zapatero, y M. Muñoz de Morales Romero (dirs.). Cooperar y castigar: el caso Puigdemont. Cuenca: Ediciones Universidad de Castilla-la Mancha.

Bang Fuglsang Madsen Sørensen, H. (2016). Mutual trust. Blind trust or general trust with exceptions? The CJEU hears key cases on the European Arrest Warrant. EU Law Analysis. Expert insight into EU law developments [blog], 182-2016. Disponible en: https://bit.ly/2y6gwGP.

Barbe, E. (2006). El principio de doble incriminación. En L. Arroyo Zapatero, M. Muñoz de Morales Romero y A. Nieto Martín (coords.). La orden de detención y entrega europea. Cuenca: Portal Iberoamericano de las Ciencias Penales, Instituto de Derecho Penal Europeo e Internacional, Universidad de Castilla-La Mancha.

Bassiouni, M. Ch. (1974). International extradition and world public order. Leiden: Sijthoff.

Bay Larsen, L. (2012). Some Reflections on Mutual Recognition in the Area of Freedom, Security and Justice. En P. Cardonnel, A. Rosas y N. Wahl (eds.). Constitutionalising the EU Judicial System: Essays in Honour of Pernilla Lindh. Oxford: Hart Publishing.

Cobreros Mendazona, E. (2014). Efectos de la sentencia prejudicial. En R. Alonso García y J. I. Ugartemendía Eceizabarrena (dirs.). La cuestión prejudicial europea. Oñati: Instituto Vasco de Adminitración Pública.

De Jorge Mesas, L. F. (2016). Reconocimiento de las resoluciones penales en la Unión Europea. Valencia: Tirant lo Blanch.

Falkiewicz, A. (2018). The Double Criminality Requirement in the Area of Freedom, Security and Justice-Reflections in Light of the European Court of Justice Judgment of 11 January 2017, C-289/15, Criminal Proceedings against Jozef Grundza. European Criminal Law Review, 7 (3), 258-274. Disponible en: https://doi.org/10.5771/2193-5505-2017-3-257.

Fich, Ch., Humlebaek, C., Just, S. N., Lonning, E. y Müller, H. H., (2012). Legitimidad del poder supranacional: ¿una Constitución Europea? En I. Baron, C. Fich, M. Herslund y M. P. Lorenzo (eds.). De Leviatán a Lisboa. Camino del Cons- 
titucionalismo Europeo (pp. 151-195). Madrid: Centro de Estudios Políticos y Constitucionales.

Fichera, M. (2011). The implementation of the European Arrest Warrant in the European Union. Law, policy and practice. Antwerpen: Intersentia.

Gimbernat Ordeig, E. (2018). Alemania, obligada a entregar a Puigdemont por rebelión. El Mundo, 16-4-2018. Disponible en: https://bit.ly/2IZwiGf.

Gómez de Liaño Fonseca Herrero, M. (2006). El principio de reconocimiento mutuo como fundamento de la cooperación judicial penal y sus efectos en los ordenamientos de los Estados miembros. Revista de Derecho de la Unión Europea, $10,155-178$.

Grandi, C. y Bernardi, A. (2006). Amnistía. La prescripción del delito y de la sanción. En M. M. de Morales Romero, L. A. Arroyo Zapatero y A. Nieto Martín (coords.). La orden de detención y entrega europea (pp. 257-282). Cuenca: Universidad de Castilla-La Mancha.

Hoyos Sancho, M. de (2005). El principio de reconocimiento mutuo de resoluciones penales en la Unión Europea:jasimilación automática o corresponsabilidad? Revista de Derecho Comunitario Europeo, 22, 807-833.

Janssens, C. (2013). The Principle of Mutual Recognition in EU LAW. Oxford: Oxford University Press. Disponible en: https://doi.org/10.1093/acprof:oso/9780199673032.001.0001.

Jimeno Bulnes, M. (2005). La adopción de medidas cautelares de carácter personal con motivo de la ejecución de una orden europea de detención y entregal. Revista Penal, 16, 106-122.

Jimeno Bulnes, M. y Ruz Gutiérrez, P. (2015). La orden europea de detención y entrega. En C. Arangüena Fanegó, M. Hoyos Sancho y C. Rodríguez Medel (coords.). Reconocimiento mutuo de resoluciones penales en la Unión Europea. Análisis teórico-práctico de la Ley 23/2014, de 20 de noviembre (pp. 35-104). Madrid: Editorial Aranzadi.

Klimek, L. (2016). Implementation of the grounds for non-execution the European Arrest Warrant: Lex Ferenda towards the Act No. 154/2010 Coll. On the European Arrest Warrant. The Lawyer Quarterly, 6, 8-9.

Klip, A. (2016). European criminal Law, an interpretative approach. Cambridge: Intersentia.

Lenaerts, K. (2015). The principle of mutual recognition in the area of Freedom, Security and Justice. The fourth annual Sir Jeremy Lever lecture all souls College, University of Oxford. Disponible en: https://bit.ly/2DYPBlp.

Luchtman, M. (2013). Choice of forum and the prosecution of cross-border crime in the European Union. What role for the legality principle? En M. Luchtman (ed.). Choice of forum in cooperation against EU financial crime - Freedom, security and justice and the protection of specific EU-interests (pp. 3-61). The Hague: Eleven.

Mangas Martín, A. (2013). La secesión de territorios en un Estado miembro: efectos en el derecho de la Unión Europea. Revista de Derecho de la Unión Europea, 25, 47-68. 
- (2018). Euroorden versus extradición: discordancias en el (des)concierto europeo. Real Instituto Elcano. ARI 50/18. Disponible en: https://bit.ly/2DU2NI8.

Marguery, T. (2011). EU Citizenship and European Arrest Warrant: The Same Rights for All? Merkourios, 27 (73), 84-91.

Miguel Zaragoza, J. de (2003). Algunas consideraciones sobre la Decisión Marco relativa a la orden de detención europea ya los procedimientos de entrega en la perspectiva de la extradición. Actualidad Penal, (1), 139-236.

Mitsilegas, V. (2016). EU Criminal Law after Lisbon. Oxford; Portland: Hart Publishing.

Muñoz de Morales Romero, M. (2017). ¿Cómo functiona la orden de detención y entrega europea? El caso del ex-president y sus consellers como ejemplo. Diario La Ley, 9096, 1.

Nieto Martín, A. (2018). Reconocimiento mutuo, orden público e identidad nacional: la doble incriminación como ejemplo. La Ley Unión europea, 18, 21.

Peers, S. (2011). Court of Justice: the NS and ME Opinions-The Death of Mutual Trust? Disponible en: https://bit.ly/2DUh7jR.

Plachta, M. (1989). The Role of Double Criminality Requirement in International Cooperation in Penal Matters. En N. Jareborg (ed.). Double Criminality: Studies in International Criminal Law. Uppsala: Iustut.

Plachta, M. (2003). European Arrest Warrant: Revolution in Extradition? European Journal of Crime, Criminal Law and Criminal Justice, 11, 170-178. Disponible en: https://doi.org/10.1163/157181703322604776.

Ripoll Carulla, S. (2014). España ante los tribunales internacionales de la Unión Europea. Cuestiones de política judicial. Bilbao: Instituto Vasco de Administraciones Públicas.

Ruiz Yamuza, F. (2017). ¿Réquiem por el principio de confianza mutua? Reconocimiento mutuo y tutela judicial de derechos fundamentales en la jurisprudencia del TJUE a propósito de la Orden de Detención Europea. Revista General de Derecho Europeo, 43, 219-228.

Sánchez Legido, A. (2007). La euro-orden, el principio de doble incriminación y la garantía de los derechos fundamentales. Revista Electrónica de Estudios Internacionales, 14, $56 \mathrm{pp}$.

Sarmiento, D. (2018). The Strange (German) Case of Mr. Puigdemont's European Arrest Warrant. VerfBlog [blog], 4-11-2018. Disponible en: https://dx.doi. org/10.17176/20180411-141130.

Schermers, H. G. (1983). Judicial protection in the European Communities. Deventer; Boston: Kluwer Law and Taxation Publishers. Disponible en: https://doi. org/10.1007/978-94-017-4412-6.

Vandersanden, G. (2013). Renvoi préjudiciel en droit européen. Brussels: Bruylant.

Vidal Fernández, B., Arangüena Fanego, C. (coord.). (2005). Cooperación Judicial Penal en la UE: la orden europea de detención y entrega (pp. 52-56). Valladolid: Lex Nova.

Vogel, J. (2001a). Abschaffung der Auslieferung? Kritische Anmerkungen zur Reform des Auslieferungsrechts in der Europäischen Union. Juristenzeitung, 937-943. 
- (2001b). ¿ Supresión de la extradición? Observaciones críticas en relación con la reforma de la legislación en materia de extradición en la Unión Europea. Cuadernos de Derecho Judicial, (7), 171-198.

(2004). Perspektiven des internationalen Strafprozessrechts. Heidelberg: C. F. Müller.

(2007). Cooperación Penal: cinco tendencias. Cinco propuestas para una acción futura. Derecho Penal de la Unión Europea. Situación actual y perspectivas de futuro. En L. Arroyo Zapatero y A. Nieto Martín (dirs.). Cuenca: Ediciones de la Universidad de Castilla-La Mancha. 